\title{
ANALISIS PENGENDALIAN KUALITAS KEMASAN GLUKOSA DENGAN PETA KENDALI P DI PT. BUDI STARCH \& SWEETENER TBK.LAMPUNG TENGAH
}

\author{
Emy Khikmawati, Heri Wibowo, Irwansyah \\ Program Studi Teknik Industri Universitas Malahayati \\ Jl. Pramuka No. 27 Kemiling Bandar Lampung 35153 \\ e-mail: emy_khikmawati@yahoo.com; heriwibowo_ti@yahoo.co.id
}

\begin{abstract}
ABSTRAK
Permasalahan yang dihadapi dalam program kualitas yang baik, yang akan secara efektif mengeliminasi pemborosan dan meningkatkan kemampuan bersaing perusahaan, harus diwujudkan. Untuk itu dilakukan penelitian yang bertujuan menganalisis bagaimana pelaksanaan pengendalian kualitas kemasan glukosa dengan metode SQC (Statistical Quality Control) dan menemukan penyebab terjadinya cacat produk Glukosa dengan kemasan jerigen 20 liter proses sacharification, decolorization, deionization dan evaporation. Metode menggunakan alat bantu statistik berupa check sheet, histogram, peta kendali p, diagram Pareto dan diagram sebeb-akibat. Hasil analisis peta kendali p menunjukkan bahwa proses berada dalam keadaan tidak terkendali atau masih mengalami penyimpangan. Prioritas perbaikan yang perlu dilakukan untuk menekan jumlah cacat dapat dilakukan pada 2 jenis kerusakan yang dominan yaitu kerusakan kemasan tutup (43,75\%) dan volume (40,34\%). Faktor-faktor yang mempengaruhi kerusakan produk adalah mesin, metode, lingkungan. Sehingga perusahaan dapat mengambil tindakan pencegahan serta perbaikan kerusakan.
\end{abstract}

Kata kunci: Kualitas, Glukosa, Peta Kendali P, Kemasan Glukosa.

\section{ABSTRACT}

The problems encountered in a good quality program, which will effectively eliminate waste and increase the company's competitive ability, must be realized. For this reason, a study was conducted which aimed to analyze how the implementation of glucose quality control using the SQC (Statistical Quality Control) method and to find the cause of defects in glucose products with 20 liter jerry can packaging process sacharification, decolorization, deionization and evaporation. The method uses statistical tools in the form of check sheets, histograms, p control charts, Pareto diagrams and sebeb-effect diagrams. The results of the analysis of $p$ control charts indicate that the process is in a state of uncontrolled or still experiencing irregularities. Priority of repairs that need to be done to reduce the number of defects can be done on 2 types of damage that are dominant namely damage to the lid packaging (43.75\%) and volume (40.34\%). Factors affecting product damage are machinery, methods, environment. So companies can take preventative measures and repair damage.

Keywords: Quality, Glucose, Control Map P, Glucose Packaging.

\section{PENDAHULUAN}

Perusahaan memiliki persaingan tinggi untuk dituntut berkompetesi dengan perusahaan lain di dalam industry. Salah satu cara perusahaan agar bisa bersaing di nasional maupun di internasional adalah dengan memberikan perhatian penuh terhadap kualitas produk yang dihasilkan oleh perusahaan sehingga bisa mengungguli produk yang dihasilkan oleh pesaing. Melalui cara itu perusahaan dapat bertahan untuk jangka panjang sehingga perusahaan tersebut dapat berjalan dengan baik untuk menghasilkan suatu produk yang bagus dan bermutu. Proses produksi telah dilaksanakan dengan baik, pada kenyataannya seringkali masih ditemukan ketidaksesuaian antara produk yang dihasilkan dengan yang diharapkan, permasalahan dimana kualitas produk yang dihasilkan tidak sesuai dengan standar, atau dengan kata lain produk yang dihasilkan mengalami kerusakan/ cacat produk. Hal tersebut disebabkan adanya penyimpangan-penyimpangan dari berbagai faktor, baik yang berasal dari bahan baku, tenaga kerja maupun kinerja dari fasilitas mesin 
yang digunakan dalam proses produksi tersebut. Agar supaya produk yang dihasilkan tersebut mempunyai kualitas sesuai dengan standar yang ditetapkan perusahaan dan sesuai dengan harapan konsumen, maka perusahaan harus melakukan kegiatan yang berdampak pada kualitas yang dihasilkan dan menghindari banyaknya produk yang rusak/cacat ikut terjual ke pasar. Dari observasi awal pada PT Budi Starch \& Sweetener Tbk divisi Glukosa terhadap data yang ada di perusahaan terutama pada bagian produksi dengan kemasan jerigen 20 liter banyak produk cacat ditemukan dalam proses sacharification, decolorization, deionization dan evaporation. Dari proses tersebut akan menentukan parameter mutu utama glukosa yaitu $\mathrm{pH}$, Brix, warna dan Dextrose Equivalent (DE). Dalam merumuskan bagaimana pelaksanaan pengendalian kualitas kemasan glukosa di PT. Budi Starch \& Sweetener Tbk, dengan metode peta kendali P, maka penelitian bertujuan untuk menganalisis bagaimana pelaksanaan pengendalian kualitas kemasan glukosa di PT Budi Starch \& Sweetener Tbk Divisi Glukosa,Lampung Tengah dengan metode SQC (Statistical Quality Control) dan menemukan penyebab terjadinya cacat produk Glukosa dengan kemasan jerigen 20 liter proses sacharification, decolorization, deionization dan evaporation. Kualitas didefinisikan sebagai jumlah dari atribut atau sifat-sifat sebagaimana dideskripsikan di dalam produk (dari jasa) yang bersangkutan". Pengendalian kualitas adalah merupakan suatu aktivitas (manajemen perusahaan) untuk menjaga dan mengarahkan agar kualitas produk (dan jasa) perusahaan dapat dipertahankan sebagaimana yang telah direncanakan [1]. Pengendalian kualitas statistik (statistical quality control) adalah alat yang sangat berguna dalam membuat produk sesuai dengan spesifikasi sejak dari awal proses hingga akhir proses [2]. Statistical Quality Control (SQC) merupakan suatu sistem yang dikembangkan untuk menjaga standar yang uniform dari kualitas hasil produksi, pada tingkat biaya yang minimum dan merupakan bantuan untuk mencapai efisiensi [3]. Metode SQC terdapat 2 cara yaitu dengan menggunakan peta kendali (control chart) dan diagram tulang ikan (fishbone chart). Peta kendali $p$ dalam pengendalian kualitas produk dapat mengindentifikasikan kualitas produk berada di luar batas kendali. Manfaat yang bisa didapat dengan melakukan pengendalian kualitas yaitu tidak banyak produk yang rusak, sehingga produktivitas tetap terjaga [4].

\section{METODOLOGI}

Metode yang digunakan dalam penelitian ini adalah deskriptif kuantitatif. Metode kuantitatif adalah metode penelitian berlandaskan filsafat positifme yang digunakan untuk meneliti pada populasi dan sampel tertentu dengan pengumpulan data menggunakan instrument penelitian, dan analisis data bersifat kuantitatif/statistik yang tujuan untuk menguji yang telah ditetapkan [5]. Dengan melakukan pengamatan langsung di lapangan pengambilan dan pengolahan data dilakukan dengan mengunakan metode pengendalian

kualitas statistik. Data yang digunakan adalah kemasan tutup, Warna, Volume, yang terkandung di dalam Glukosa. Pengolahan data dilakukan dengan mengunakan metode pengendalian kualitas statistik, yaitu, peta kontrol, dan fishbone diagram (cause effect diagram) [6]. Langkah dalam tahapan penelitian:

a. Mengumpulkan data menggunakan check sheet

b. Membuat histogram

c. Membuat peta kendali $p$

d. Melakukan uji kecukupan data

e. Menentukan prioritas perbaikan (menggunakan diagram Pareto) mencari faktor penyebab yang dominan (dengan diagram sebab akibat)

f. Membuat rekomendasiusulan perbaikan kualitas 


\section{HASIL DAN PEMBAHASAN}

Pengendalian kualitas secara statistik pertama adalah membuat check sheet dari jenis kerusakan produk, dilanjutkan untuk memudahakan dalam melihat lebih jelas kerusakan yang terjadi sesuai dengan histogram data produk rusak tersebut disajikan dalam bentuk grafik balok.

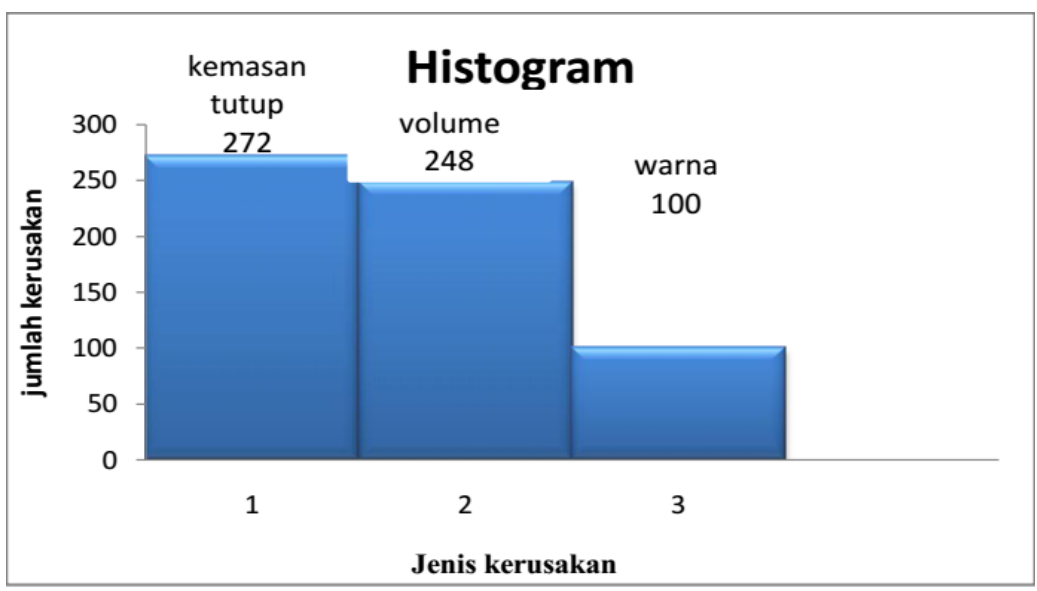

Gambar 1. Histogram kerusakan pada PT. Budi Starch \& Sweetener

Dari histogram yang telah ditunjukkan pada Gambar 1, dapat dilihat bahwa jenis kerusakan yang terjadi adalah rusak kemasan tutup dengan jumlah kerusakan sebanyak 272. Jumlah jenis kerusakan volume, dan warna yang secara berturut-turut berjumlah 248 , dan 100 .

\section{Peta Kendali $p$}

Peta kendali $p$ mempunyai manfaat untuk membantu pengendalian kualitas produksi serta dapat memberikan informasi mengenai kapan dan dimana perusahaan harus melakukan perbaikan kualitas [5].

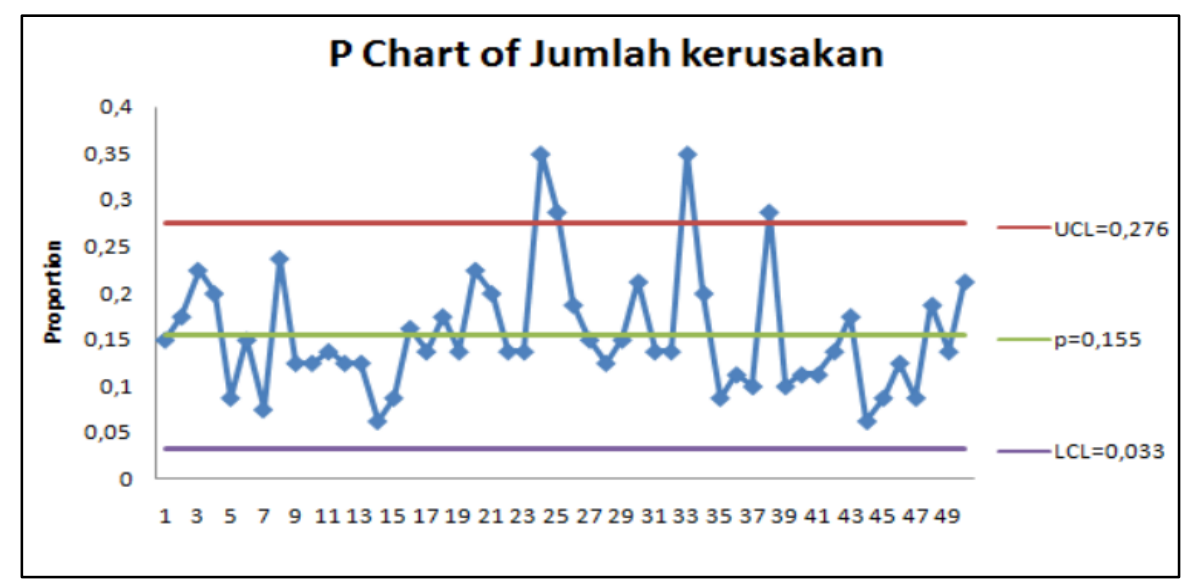

Gambar 2. Peta Kendali p Proporsi Kerusakan

Berdasarkan Gambar 2 dapat dilihat bahwa data yang diperoleh tidak seluruhnya berada dalam batas kendali yang telah ditetapkan tetapi masih ada 4 titik yang keluar, ada 46 titik yang berada di dalam batas kendali, sehingga bisa dikatakan proses tidak terkendali. Hal ini menunjukkan masih adanya penyimpangan. Menyatakan bahwa pengendalian kualitas di PT. Budi Starch \& Sweetener memerlukan adanya perbaikan. Karena adanya titik yang menyimpang dan tidak beraturan yang menunjukkan bahwa produk masih mengalami penyimpangan setelah dilakukannya pengujian sampel. 


\section{Uji Keseragaman data}

Dari peta kendali $p$ di atas dapat dilihat ada beberapa titik yang menyimpang dari UCL dan LCL, oleh karena itu perlu uji dibuat suatu batas kendali baru terhadap produk atau data yang diteliti agar dapat diperoleh suatu keragaman data. Hal ini dapat dilakukan dengan menghilangkan data yang mempunyai cacat lebih kecil dari LCL atau lebih besar dari UCL. Adapun data yang menyimpang diteliti ada 4 data (titik) yaitu 24,25,33 dan 38.

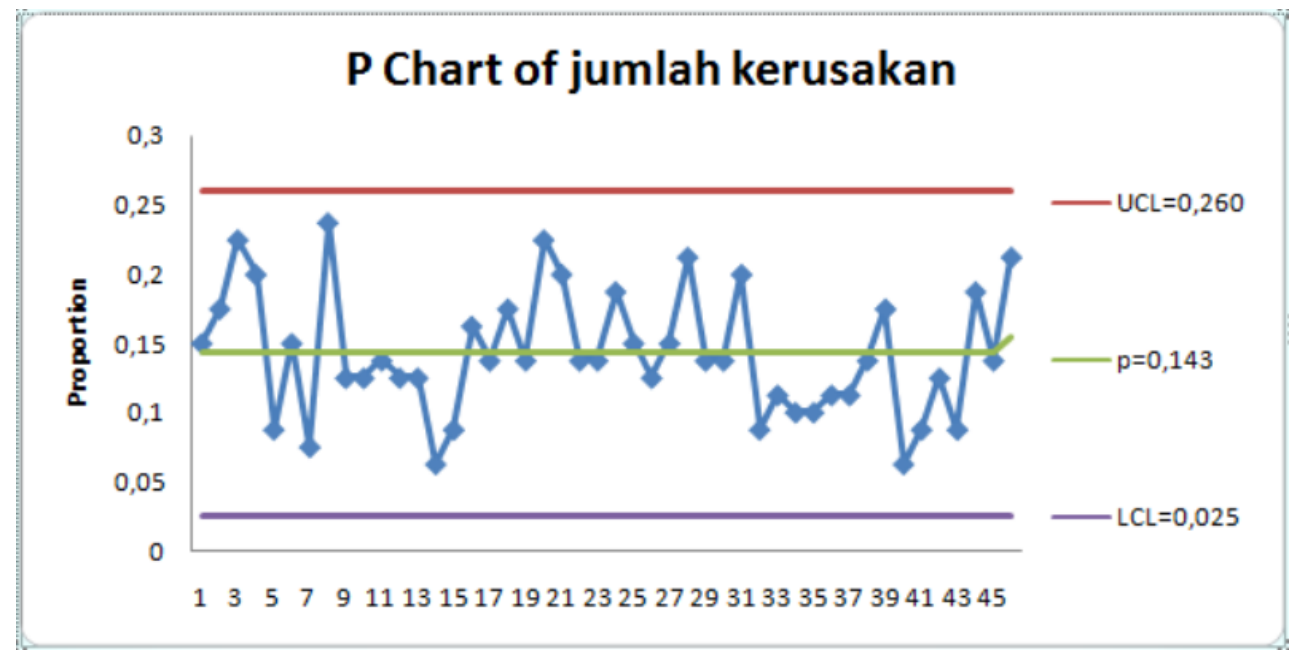

Gambar 3. Peta Kendali p Proporsi Kerusakan Setelah Diperbaiki

Dari Gambar 3 setelah revisi karena dalam peta kendali terdapat data yang berada di luar batas kendali, yaitu dari observasi $24,25,33$ dan 38. Data yang keluar tersebut dihilangkan dan menghitung batas kendali yang baru. Berdasarkan Gambar tersebut peta kendali $p$ setelah direvisi diatas dapat dilihat bahwa data yang diperoleh telah berada dalam batas kendali yang telah ditetapkan sehingga bisa dikatakan bahwa data telah terkendali. Adapun penyebab suatu data keluar dari batas peta kendali disebabkan oleh beberapa faktor yang menyebabkan kerusakan pada suatu produk kemasan glukosa, faktor tersebut akan dianalisis pada diagram Fishbone atau sebab akibat.

\section{Diagram Pareto}

Diagram Pareto adalah diagram yang digunakan untuk mengidentifikasi, mengurutkan dan bekerja untuk menyisihkan kerusakan produk secara permanen.

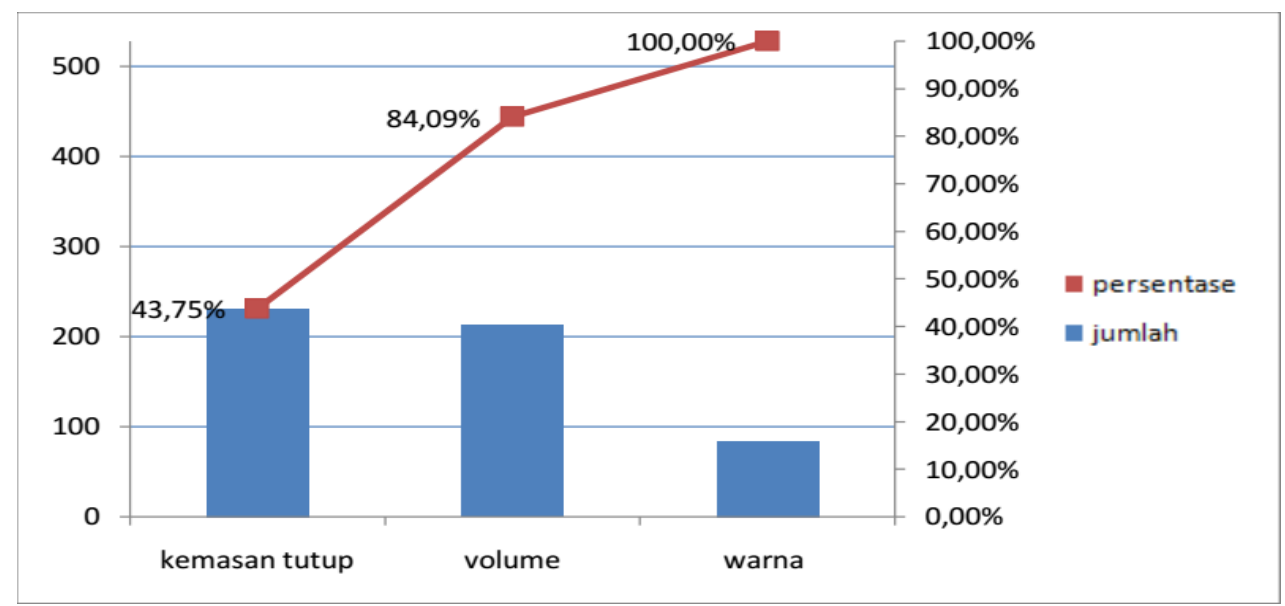

Gambar 4. Diagram Pareto 
Dari hasil pengamatan pada Gambar 4 dapat diketahui kerusakan yang terjadi pada produksi kemasan jerigen glukosa yang terjadi pada produksi September-Oktober didominasi oleh 2 jenis kerusakan yaitu kemasan tutup dengan persentase 43,75\%, kerusakan karena volume sebesar 40,34\%, dan warna dengan persentase 15,91\% dari jumlah sampel produksi. Jadi perbaikan dapat dilakukan dengan memfokuskan 2 jenis kerusakan terbesar yaitu kemasan tutup,dan volume.

\section{Diagram Sebab Akibat (Fishbone Chart)}

Diagram sebab akibat memperlihatkan hubungan antara permasalahan yang dihadapi dengan kemungkinan penyebab serta faktor-faktor yang mempengaruhinya. Kurang teliti dalam tutup kemasan jerigen 20 liter menyebabkan defect/cacat. Hal ini disebabkan dari faktor: manusia,lingkungan dan metode untuk kemasan tutup.

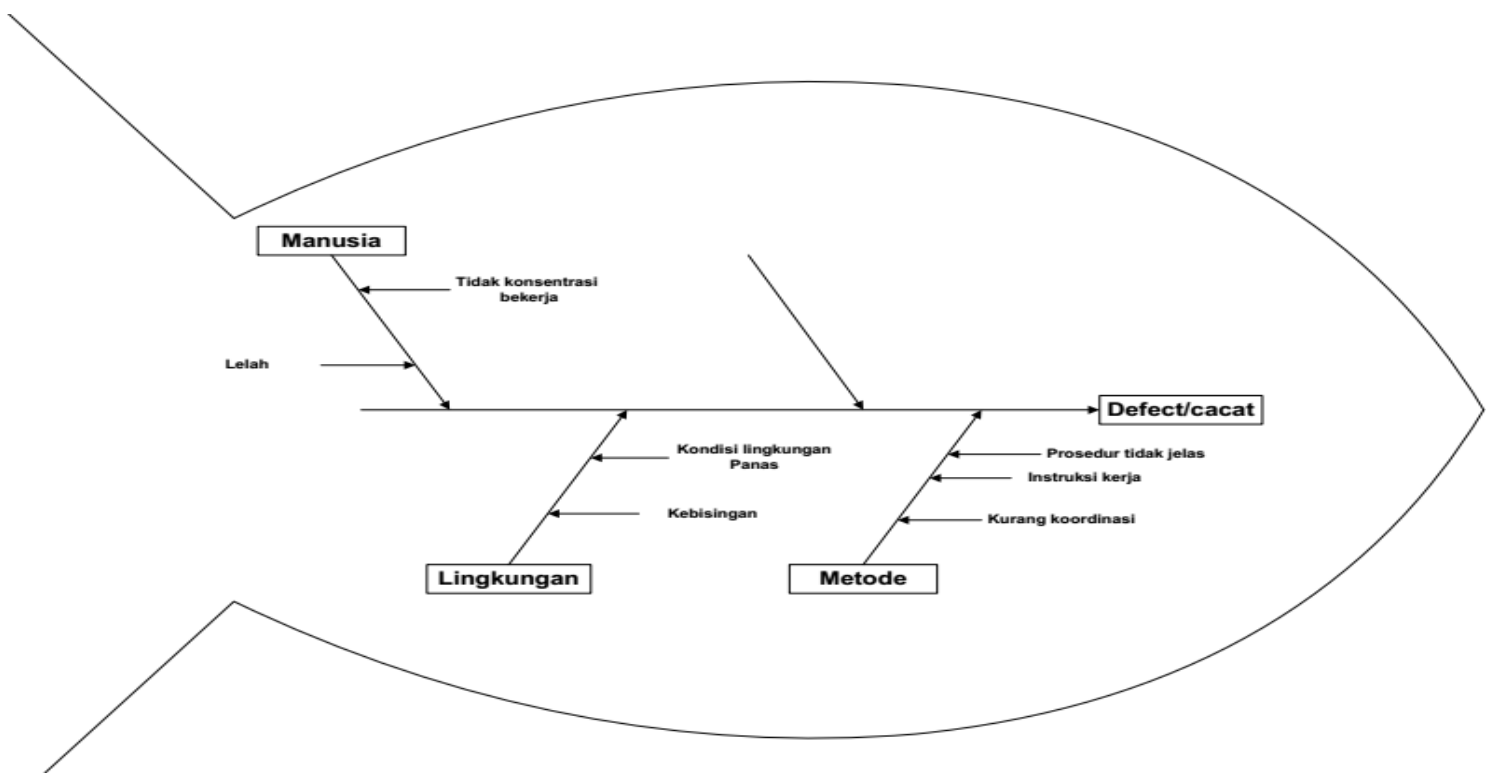

Gambar 5. Diagram Sebab Akibat Untuk Kemasan Tutup

Untuk faktor volume, pengisian glukosa cair ke dalam jerigen yang tidak sesuai dengan volume. Hal ini disebabkan dari faktor; manusia, mesin, lingkungan dan metode.

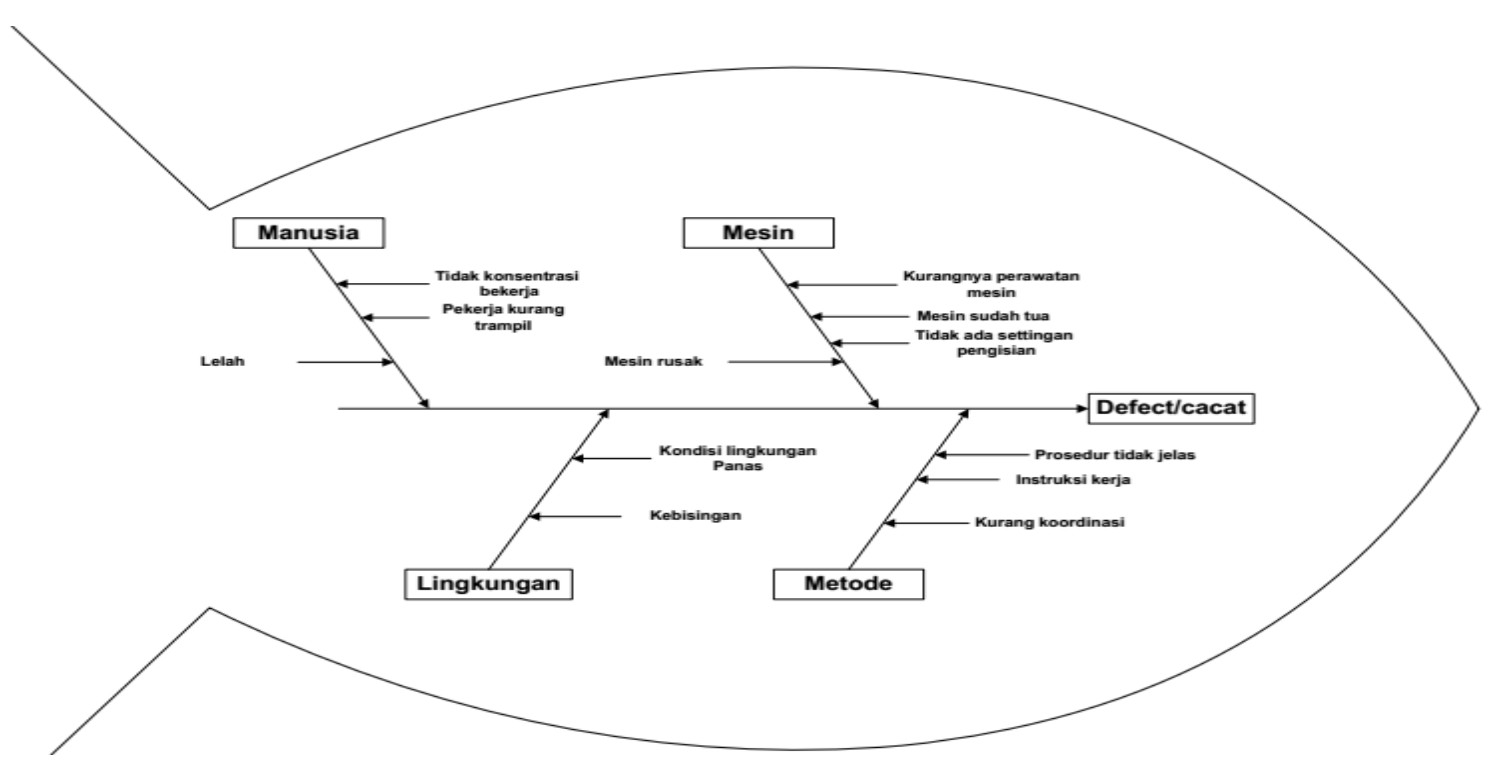

Gambar 6. Diagram Sebab Akibat Untuk Volume 
Tbk. Lampung Tengah

Emy Khikmawati, Heri Wibowo, Irwansyah

\section{Usulan Tindakan Untuk Mengatasi Penyebab Kerusakan}

Setelah mengetahui penyebab kerusakan atas kemasan glukosa yang terjadi, maka disusun suatu rekomendasi atau usulan tindakan perbaikan secara umum dalam upaya menekan tingkat kerusakan produk sebagai berikut.

Tabel 1. Usulan Tindakan Untuk Kerusakan Kemasan Tutup

\begin{tabular}{|c|c|c|}
\hline Faktor & Penyebab & Usulan tindakan perbaikan \\
\hline Manusia & $\begin{array}{l}\text { 1. Tidak konsentrasi dalam bekerja } \\
\text { karena kondisi lingkungan panas } \\
\text { sehingga salah dalam memposisikan } \\
\text { kemasan tutup. } \\
\text { 2. Lelah sehingga } \\
\text { ada motivasi untuk terus bekerja } \\
\text { dengan benar. }\end{array}$ & $\begin{array}{l}\text { 1. Lingkungan kerja perlu diperbaiki, dengan cara } \\
\text { melakukan penghijauan secara terus menerus } \\
\text { sehingga suasana tempat kerja menjadi sejuk. } \\
\text { 2. Pihak perusahaan perlu Mengadakan evaluasi } \\
\text { kenyamanan pada saat bekerja, karena semakin } \\
\text { nyaman tempat kerja konsentrasi pekerja semakin } \\
\text { meningkat. }\end{array}$ \\
\hline Metode & $\begin{array}{l}\text { 1. Prosedur tidak jelas } \\
\text { 2. Instruksi kerja } \\
\text { 3. Kurang koordinasi }\end{array}$ & $\begin{array}{l}\text { 1. Harus ada komunikasi antara karyawan satu } \\
\text { dengan yang lain agar bisa mengecek tutup } \\
\text { kemasan dengan sesuai. } \\
\text { 2. Instruksi kerja yang diberikan secara tertulis } \\
\text { disertai penjelesan secara lisan untuk } \\
\text { mengarahkan karyawan,kerja yang baik } \\
\text { 3. Perlu diadakan pelatihan tentang kerja sama antar } \\
\text { pekerja dan penanggung jawab, agar jika terjadi } \\
\text { kesalahan mudah teridentifikasi. }\end{array}$ \\
\hline Lingkungan & $\begin{array}{l}\text { 1. Kondisi lingkungan panas } \\
\text { 2. Kebisingan }\end{array}$ & $\begin{array}{l}\text { 1. Menambah sirkulasi udara pada ruangan dan } \\
\text { melakukan penghijauan di sekitar perusahaan. } \\
\text { 2. Jarak ruangan pengisian harus sedikit jauh dari } \\
\text { proses awal pembuatan. }\end{array}$ \\
\hline
\end{tabular}

Tabel 2. Usulan Tindakan Untuk Kerusakan Volume

\begin{tabular}{|c|c|c|}
\hline Faktor & Penyebab & Usulan tindakan perbaikan \\
\hline Manusia & $\begin{array}{l}\text { 1. Tidak konsentrasi dalam bekerja } \\
\text { karena kondisi lingkungan panas } \\
\text { sehingga salah dalam memposisikan } \\
\text { kemasan tutup. } \\
\text { 2. Pekerja kurang trampil } \\
\text { 3. Lelah }\end{array}$ & $\begin{array}{l}\text { 1. Lingkungan kerja perlu diperbaiki, dengan cara } \\
\text { melakukan penghijauan secara terus menerus } \\
\text { sehingga suasana tempat kerja menjadi sejuk. } \\
\text { 2. Memberikan pengarahan dan peringatan kepada } \\
\text { pekerja apabila melakukan kesalahan. } \\
\text { 3. Pihak perusahaan perlu mengadakan evaluasi } \\
\text { kenyamanan pada saat bekerja karena semakin } \\
\text { nyaman tempat kerja konsentrasi pekerja semakin } \\
\text { meningkat. }\end{array}$ \\
\hline Mesin & $\begin{array}{l}\text { 1. Kurang perawatan } \\
\text { 2. Mesin sudah tua } \\
\text { 3. Tidak ada settingan pengisian } \\
\text { 4. Mesin rusak }\end{array}$ & $\begin{array}{l}\text { 1. Perlu melakukan perawatan mesin yang lebih } \\
\text { sering untuk mengurangi kerusakan mesin. } \\
\text { 2. Perlu pembaruan mesin dengan teknologi terbaru, } \\
\text { agar pengisiannya sesuai. } \\
\text { 3. Perlu dilakukan pengembangan teknologi untuk } \\
\text { pengisian glukosa. } \\
\text { 4. Perlu perawatan atau mengganti dengan mesin } \\
\text { baru. }\end{array}$ \\
\hline Metode & $\begin{array}{l}\text { 1. Prosedur tidak jelas. } \\
\text { 2. Instruksi kerja } \\
\text { 3. Kurang koordinasi }\end{array}$ & $\begin{array}{l}\text { 1. Harus ada komunikasi antara karyawan satu } \\
\text { dengan yang lain agar bisa mengecek tutup } \\
\text { kemasan dengan sesuai. } \\
\text { 2. Instruksi kerja yang diberikan secara tertulis } \\
\text { dengan disertai penjelesan. secara lisan untuk } \\
\text { mengarahkan karyawan dengan kerja yang baik. } \\
\text { 3. Perlu diadakan pelatihan tentang kerja sama antar } \\
\text { pekerja dan penanggung jawab, agar jika terjadi } \\
\text { kesalahan mudah teridentifikasi. }\end{array}$ \\
\hline Lingkungan & $\begin{array}{l}\text { 1. Kondisi lingkungan panas } \\
\text { 2. Kebisingan }\end{array}$ & $\begin{array}{l}\text { 1. Menambah sirkulasi udara pada ruangan dan } \\
\text { melakukan penghijauan di sekitar perusahaan. } \\
\text { 2. Jarak ruangan pengisian harus sedikit jauh dari } \\
\text { proses awal pembuatan }\end{array}$ \\
\hline
\end{tabular}




\section{KESIMPULAN}

Dari hasil penelitian yang dilakukan, disimpulkan, peta kendali $p$ dalam pengendalian kualitas produk dapat mengindentifikasikan kualitas produk berada di luar batas kendali, hal ini menunjukkan bahwa sampel dari hasil produksi masih mengalami penyimpangan. Adapun setelah revisi menunjukkan titik sudah terkendali atau tidak ada data penyimpangan. Dan hasil Diagram Pareto, prioritas perbaikan yang perlu dilakukan oleh perusahaan untuk menekan atau mengurangi jumlah kerusakan yang terjadi dalam produksi dapat dilakukan pada 2 jenis kerusakan yang dominan terjadi yaitu kerusakan kemasan tutup $(43,75 \%)$, dan volume $(40,34 \%)$, serta faktor yang mempengaruhi dan menjadi penyebab kerusakan produk adalah manusia, mesin, metode dan lingkungan. Manfaat yang bisa didapat dengan melakukan pengendalian kualitas maka kualitas kemasan glukosa produk agar tidak banyak produk yang rusak, tetap terjaga.

\section{DAFTAR PUSTAKA}

[1]. Ahyari, Agus. 2000. Manajemen Produksi. BPFEUGM. Yogyakarta.

[2]. Yamit, Zulian. 2013. Manajemen Kualitas Produk \& Jasa. Ekosinia. Jakarta.

[3]. Assauri, Sofjan. 2004. Manajemen Produksi dan Operasi. LPFE - UI. Edisi Revisi. Jakarta.

[4].Sugiyono. 2013. Metode Penelitian Bisnis. Alfabeta. Bandung.

[5].Muhammad, S.H.E, 2017. Pengendalian Kualitas dengan Menggunakan Metode Statistical Quality Control (SQC) untuk meminimumkan produk gagal pada toko roti Barokah Bakery. Jurnal Penelitian Ilmu Ekonomi WIGA, Vol.7, Hal 15-22.

[6].Russell, Roberta \& Taylor, Bernard W. 2006. Operations Management. 5th Edition. John Wiley \& Sons. 